\title{
Impact of blindness, visual impairment and cataract surgery on quality of life and visual functioning among adults aged 40 years and above in Sri Lanka
}

\author{
G V S Murthy ${ }^{1,2}$, E Schimdt ${ }^{3}$, C Gilbert ${ }^{1}, \mathrm{~K}$ Edussuriya ${ }^{4}$, H B Pant ${ }^{2}$ on behalf the Sri Lanka National \\ Blindness, Visual Impairment and Disability Steering Committee and Survey Team ${ }^{5}$
}

\begin{abstract}
Aims To assess associations of visual function (VF) and quality of life (QOL) by presenting visual acuity (PVA) and causes of blindness and visual impairment.

Methods Multi-stage cluster random sampling was used to identify a nationally representative sample of persons aged $\geq 40$ years in Sri Lanka. Previously validated VF and QOL measurement instruments were administered to participants who were blind or severely visually impaired due to cataract, or refractive errors, those with moderate severe visual impairment of any cause and a sample of those with normal/near normal vision (VA $\geq 6 / 12$ in the better eye). Questionnaires were also administered to persons who had undergone cataract surgery in one or both eyes and had a postoperative vision $\geq 6 / 60$.
\end{abstract}

Results The Cronbach $\alpha$ coefficients showed that the VF and QOL subscales had satisfactory internal consistency and reliability. Mean VF/QOL scores of individuals who were blind (presenting $V A<3 / 60$ in the better eye) were significantly lower and the maximal difficulty in performing VF tasks and QOL-related activities. Persons visually impaired from cataract had the greatest difficulty in performing VF activities and QOL domains on all the items in the VF and QOL questionnaires. Persons operated for cataract had much better VF/QOL outcomes compared to those who were visually impaired due to cataract.

Conclusions VF and QOL self-reported questionnaires are very useful to monitor patient-reported functional benefit from blindness control interventions in low and middle-income countries like Sri Lanka.

\author{
Ceylon Medical Journal 2018; 63 (S2): s26-s32
}

DOI: http://doi.org/10.4038/cmj.v63i5.8739

\section{Introduction}

Recent decades have seen greater recognition of the value of patient-reported assessment of visual function (VF) and vision-related quality of life (QOL). This is because visual acuity (VA) is only one of several visual functions, the others including visual fields, colour vision and contrast sensitivity, and measurement of loss of visual acuity alone cannot capture the impact on abilities to undertake everyday visual tasks [1,2]. The increased emphasis on functional outcomes in ophthalmology has led to the development of more than a dozen VF instruments over the past 30 years [3]. The majority of the VF assessment instruments elicit patient's judgment about their level of difficulty in completing specific tasks which require vision [1,3-10].

VF has generally been defined as the measure of activities of daily living affected by vision while QOL describes a comprehensive picture of the burden of vision loss [1,7].

Data for this study came from the Sri Lanka national blindness, visual impairment and disability survey, and is the first study of VF and vision-related QOL at the national level in Sri Lanka. Clients' perspectives of the impact of loss of vision on their lives are useful for advocacy and prioritizing for priority setting in blindness control programs.

\begin{abstract}
${ }^{1}$ International Centre for Eye Health, Department of Clinical Research, London School of Hygiene and Tropical Medicine, London, UK and Indian Institute of Public Health, Hyderabad, India, ${ }^{2}$ Indian Institute of Public Health, Hyderabad, India, ${ }^{3}$ Sightsavers, Haywards Health, United Kingdom, ${ }^{4}$ Department of Ophthalmology, General Hospital, Kandy, Sri Lanka, ${ }^{5}$ In addition to the above, other members of the Sri Lanka National Blindness, Visual Impairment and Disability Steering Committee and Survey Team: Palitha Mahipala, Asela Pradeep Abeydeera, Ahamada Jeza, Champa Banagala, KMK Gamage, Saman Senanayake, Sunil Fernando, Lakmini Dissanayake, Nirmi Vitharana, Nimal Edirisinghe, Sunil Settinayake, RP Kumara, S A H K Wimalarathne, Attapathu AH, Priyangani MD, Bandara KRTC, Chamin Rathnayake, Y G Upali Jayarathne, Souvik Bandhopadhyaya, Mahesh Dorairaj, Sandeep Bhuttan TC, Chamin Rathnayake, Y G Upali Jayarathne, Souvik Bandhopadhyaya, Mahesh Dorairaj, Sandeep Bhuttan.
\end{abstract}

Correspondence: GVSM, e-mail: <Gvs.Murthy@lshtm.ac.uk>. Received 19 February 2018 and revised version accepted 23 June 2018.

(i) This is an open-access article distributed under the terms of the Creative Commons Attribution License, which permits unrestricted use, distribution, and reproduction in any medium, provided the original author and source are credited. 


\section{Methods}

A companion paper in this issue details the methodology used in the survey. In brief, multi-stage stratified cluster random sampling was used to identify a crosssectional nationally representative sample aged $\geq 40$ years of age. All nine provinces and a random sample of divisional secretariats were included. An initial house-tohouse enumeration identified eligible participants who were asked to attend a temporary clinical examination site set up in a convenient location within each cluster. All the core staff underwent intensive training for one week prior to the start of the survey followed by a pilot.

Among the examined participants, a subset was selected to complete the VF/QOL questionnaires. Eligible participants had to meet one of the following criteria: 1 . Have a presenting visual acuity (PVA) of $<6 / 18-6 / 60$ in the better eye (moderate visual impairment group); 2 . Have a PVA of $<6 / 60$ in the better eye with cataract being the cause of visual loss (cataract blind and SVI group); 3 . Have a PVA of $<6 / 60$ in the better eye due to uncorrected refractive (refractive errors blind and SVI group) 4. Persons operated for cataract in one or both eyes with PVA $\geq 6 / 60$ (cataract operated group), and 5. A systematic random sample of 1 in 7 of those with bilateral VA $\geq 6 / 12$ ("normal/ near normal vision' group).

Two trained interviewers verified patients' eligibility and administered the VF/QOL questionnaires.

All persons with a visual acuity of $<6 / 12(<20 / 40)$ in one or both eyes, and where an abnormality was detected had a detailed examination by an ophthalmologist who determined the cause of visual loss.

The following WHO definitions of visual loss were used, based on PVA in the better eye: $\geq 6 / 12$ not impaired (or normal/ near normal vision); $<6 / 12-6 / 18$ mild visual impairment, <6/18-6/60 moderate visual impairment; <6/ 60-3/60 SVI, and $<3 / 60$ blind [11].

\section{Visual Function and Quality of Life instruments and validation}

The interviewer-administered VF/QOL questionnaires used in this study were initially developed, validated and used in a clinical trial of cataract surgery in India [7]. They have subsequently been used in other studies in Kenya [12], Mali [13], Pakistan [14], Nepal [15] and Nigeria [16].

The VF questionnaire measures an individual's visual capabilities and has five subscales: general vision, visual perception, peripheral vision, sensory adaptation and depth perception. The QOL questionnaire measures four subscales: self-care, mobility and social and mental wellbeing. Overall, the QOL questionnaire measures the difficulties individuals face in everyday life because of visual loss. The response scale ranges from ' 0 ' indicating great difficulty to ' 3 ' indicating no difficulty.
The English version of the instrument was translated into Sinhala and Tamil and back-translated into English for validation.

Two trained interviewers working as a team administered the interviews in a private area within the clinical examination site. Each interview took 10-15 minutes to complete.

In accordance with Fletcher's guidelines for scoring the VF and QOL questionnaires [7], subscale scores were obtained by summing all the responses to questions in a particular subscale. All subscale scores, total VF and total QOL, were linearly transformed to produce a maximum score of 100 , with 100 representing the best possible VF or QOL score and 0 representing the worst [7]. Statistical analysis was performed using Stata 13.0 (StataCorp LP, Texas, USA).

Socio-economic status was first calculated based on family assets and classifying into 4 quartiles (1st quartileupper; $2^{\text {nd }}$ quartile - upper middle; $3^{\text {rd }}$ quartile - lower middle; $4^{\text {th }}$ quartile - lowest). These were then categorized into two groups where the 'Upper' SES included the top two quartiles and the 'Lower' SES included the bottom two quartiles. Literacy status was classified into two categories (secondary level or ' $O$ ' level or below; Above secondary level or 'O' level)

Cronbach $\alpha$ coefficients were used to assess the internal consistency and reliability of the different subscales in the VF and QOL questionnaires. Anova and t-tests were used to compare means while Chi square was used to test the significance of frequencies. All analyses were performed using PVA in the better eye.

The study protocol was reviewed and approved by the institutional ethics committees of London School of Hygiene and Tropical Medicine, London, UK, the Faculty of Medicine, University of Colombo, Sri Lanka and the Indian Institute of Public Health, Hyderabad, India.

\section{Results}

A total of 6713 individuals aged $\geq 40$ years of age were enumerated. $5779(86.1 \%)$ presented for examination at a temporary clinical site in the cluster or were examined at home if they could not attend the clinical site due to health issues and were willing to be examined. Response rates were above $80 \%$ for all socio-demographic subcategories except for males where it was lower (78.9\%) (Table 1). There were no significant difference between the mean age of those enumerated (56.42 years) compared to those examined (56.67 years) $(\mathrm{t}=-1.823$; $\mathrm{p}=0.068)$ (Table 1).

2,306 participants (Male-38.1\%; Mean age 61.5 \pm 11.0 years) were administered the VF and QOL instruments. 610 had normal PVA with the remainder having varying degrees of visual loss (Table 2) and causes of visual loss (Table 3). 
The Cronbach $\alpha$ coefficients of the multi-item VF subscales and the QOL subscales were greater than 0.8 (VF: 0.9024, QOL 0.9647), indicating satisfactory internal consistency and reliability.

Mean VF scores were linearly related to the category of visual impairment - the poorer the vision, the lower the VF score in all domains (Table 2). Visual perception, sensory adaptation, peripheral vision, depth perception and total VF scores were significantly higher among those who had normal/near-normal vision compared to all other visual impairment categories. The lowest score was amongst those who were blind. Differences in the mean VF domain scores across the vision categories were statistically significant for all domains (Table 2).

Total QOL scores and VF scores for the different domains were linearly related to vision categories with the blind reporting the lowest mean scores overall and for self-care, mobility, social and mental health domains. Selfcare and mobility were only perceived as a major concern by those who were blind. The blind reported significantly higher adverse outcomes in all domains compared to all the other vision categories (Table 2).

VF/QOL scores for those visually impaired or blind from cataract or uncorrected refractive errors and those previously operated for cataract in one or both eyes, were compared with persons with normal/near normal vision or with moderate visual impairment irrespective of the underlying cause (Table 3). Persons visually impaired from cataract had the lowest VF and QOL scores overall and in all items/domains. Those with moderate visual impairment, visually impairing refractive errors and those operated for cataract in one or both eyes had comparable VF scores in most domains. Almost all groups had similar difficulty in recognizing very small objects. People with uncorrected refractive errors had problems with contrast sensitivity. It was clear that those operated for cataract had much better outcomes than those visually impaired due to cataract. The least differences were in relation to near vision activities. Differences between the groups on all the VF and QOL questions were statistically significant.

Mean VF scores for visual perception, peripheral vision, sensory adaptation, depth perception and overall mean VF scores were lowest in the cataract blind group (mean total VF score $55.8 \pm 22.5$ ) followed by the cataract operated (mean total VF score $89.1 \pm 21.3$ ) compared to the other groups including those with normal vision $(\mathrm{p}<0.001)$ (Table 3). Those blind or severely visually impaired due to uncorrected refractive errors had marginally better scores than those who had a cataract surgery in one or both eyes.

After adjusting for PVA, lower level of education was the only variable associated with total VF score (Odds ratio $0.7, p=0.01$ ) (Table 4). In contrast, QOL scores were significantly lower in the older age group $(\mathrm{OR} 4.9, \mathrm{p}<0.001)$ and in the less well educated $(\mathrm{OR} 0.5, \mathrm{p}<0.001)$

Table 1. Socio-demographic characteristics of enumerated and examined individuals

\begin{tabular}{lccc}
\hline & Enumerated & Examined & Response Rate (\%) \\
\hline Total & 6713 & 5779 & 86.1 \\
Mean age & $56.42( \pm 11.02)$ & $56.67( \pm 10.89)$ & \\
& & & \\
Age Groups & $\mathrm{t}=-1.8233 ; \mathrm{p}=0.068 ;$ & & 83.2 \\
$40-49$ years & 2053 & 1708 & 85.3 \\
$50-59$ years & 2178 & 1859 & 90.7 \\
$60-69$ years & 1570 & 1424 & 86.4 \\
$\geq 70$ years & 912 & 788 & 78.9 \\
Sex & & & 91.8 \\
Male & 2984 & 2356 & 84.5 \\
Female & 3729 & 3423 & 86.3 \\
Residence & & & 85.7 \\
Urban & 818 & 691 & 86.2 \\
Rural & 5895 & 5088 & 86.1 \\
Literacy & & & \\
$\leq$ Secondary school & 1935 & 1659 & \\
$>$ Secondary school & 4778 & 4120 & \\
Socio Economic Status & & 2517 & \\
Upper SES & 2923 & 3262 & \\
Lower SES & 3790 & & \\
\hline & & & \\
\hline
\end{tabular}


Table 2. VF/QOL scores by presenting visual acuity in the better eye

\begin{tabular}{|c|c|c|c|c|c|}
\hline Parameter & $\begin{array}{c}\text { Normal vision } \\
\text { Mean }( \pm S D)\end{array}$ & $\begin{array}{c}\text { Mild VI } \\
\text { Mean }( \pm S D)\end{array}$ & $\begin{array}{l}\text { Moderate VI } \\
\text { Mean }( \pm S D)\end{array}$ & $\begin{array}{c}\text { Severe VI } \\
\text { Mean }( \pm S D)\end{array}$ & $\begin{array}{c}\text { Blind } \\
\text { Mean }( \pm S D)\end{array}$ \\
\hline No. & 610 & 726 & 804 & 88 & 78 \\
\hline \multicolumn{6}{|c|}{ Visual Function scores (based on those responding) } \\
\hline Visual perception & $74.2(17.2)$ & $67.6(19.0)$ & $\begin{aligned} 63.8 & (21.0) \\
F=61.22 ; & p<0.001\end{aligned}$ & $56.9(23.8)$ & $42.7(26.2)$ \\
\hline Peripheral Vision & $80.0(21.8)$ & $74.5(26.6)$ & $\begin{aligned} 69.1 & (28.1) \\
F=42.31 ; & p<0.001\end{aligned}$ & $62.5(30.4)$ & $44.3(31.3)$ \\
\hline Sensory adaptation & $72.7(14.8)$ & $67.6(16.1)$ & $\begin{aligned} 65.7 & (17.4) \\
F=41.95 ; & p<0.001\end{aligned}$ & $61.2(18.5)$ & $50.0(23.4)$ \\
\hline Depth perception & $91.1(18.2)$ & $86.9(22.5)$ & $\begin{aligned} 83.7 & (24.7) \\
\mathrm{F}=30.65 ; & \mathrm{p}<0.001\end{aligned}$ & $78.5(26.8)$ & $63.7(35.0)$ \\
\hline $\begin{array}{l}\text { Total Visual } \\
\text { Function score }\end{array}$ & $79.5(14.6)$ & $74.1(17.5)$ & $\begin{aligned} 70.6 & (19.3) \\
F=60.53 ; & p<0.001\end{aligned}$ & $64.8(20.9)$ & $50.2(25.7)$ \\
\hline \multicolumn{6}{|c|}{ Quality of life scores (based on those responding) } \\
\hline $\mathrm{N}$ & 607 & 721 & 799 & 88 & 78 \\
\hline Self-care & $96.9(9.9)$ & $95.0(13.3)$ & $\begin{aligned} & 91.5(17.9) \\
& \mathrm{F}=70.1 ; \mathrm{p}<0.001\end{aligned}$ & $90.5(19.7)$ & $66.1(36.4)$ \\
\hline Mobility & $92.5(17.5)$ & $88.6(20.7)$ & $\begin{aligned} 84.0 & (25.5) \\
F=72.85 ; & p<0.001\end{aligned}$ & $79.7(27.5)$ & $47.6(38.8)$ \\
\hline Social & $87.4(21.4)$ & $81.7(24.3)$ & $\begin{aligned} 75.9 & (28.7) \\
\mathrm{F}=71.54 ; & \mathrm{p}<0.001\end{aligned}$ & $67.3(32.7)$ & $38.6(37.7)$ \\
\hline Mental & $91.6(16.5)$ & $88.0(21.4)$ & $\begin{aligned} 86.0 & (24.4) \\
F=27.47 ; & p<0.001\end{aligned}$ & $83.8(26.4)$ & $64.2(39.2)$ \\
\hline $\begin{array}{l}\text { Total Quality } \\
\text { of Life score }\end{array}$ & $92.1(14.1)$ & $88.3(17.4)$ & $\begin{array}{c}84.4(21.1) \\
\mathrm{F}=77.6 ; \mathrm{p}<0.001\end{array}$ & $80.3(22.8)$ & $53.8(33.1)$ \\
\hline
\end{tabular}

$\mathrm{VI}=$ visual impairment

Table 3. VF/QOL Mean scores by domains and vision categories

\begin{tabular}{|c|c|c|c|c|c|}
\hline \multirow[t]{2}{*}{ Parameters } & \multicolumn{5}{|c|}{ Vision Categories } \\
\hline & $\begin{array}{l}\text { Normal } \\
N=610\end{array}$ & $\begin{array}{c}\text { Moderate VI } \\
\text { any cause } \\
(<61 / 8-6 / 60) \\
N=723\end{array}$ & $\begin{array}{c}\text { Cataract } \\
\text { operated } \\
(V A \geq 6 / 60 \\
N=144\end{array}$ & $\begin{array}{c}\text { URE blind } \\
\text { and } S V I \\
(V A<6 / 60) \\
N=50\end{array}$ & $\begin{array}{c}\text { Cataract blind } \\
\text { and } S V I \\
(V A<6 / 60) \\
N=81\end{array}$ \\
\hline \multicolumn{6}{|c|}{ Visual Function scores (based on those responding) } \\
\hline Visual perception & $74.2( \pm 17.2)$ & $64.3( \pm 21.1)$ & $\begin{array}{c}60.7( \pm 19.4) \\
\mathrm{F}=53.57 ; \mathrm{p}<0.001\end{array}$ & $63.3( \pm 20.3)$ & $44.7( \pm 25.7)$ \\
\hline Peripheral vision & $80.0( \pm 21.7)$ & $69.2( \pm 28.1)$ & $\begin{array}{c}68.1( \pm 29.0) \\
\mathrm{F}=33.97 ; \mathrm{p}<0.001\end{array}$ & $68( \pm 27.9)$ & $48.5( \pm 30.9)$ \\
\hline Sensory adaptation & $72.6( \pm 14.8)$ & $66.2( \pm 17.3)$ & $\begin{array}{c}62.2( \pm 17.5) \\
\mathrm{F}=40.25 ; \mathrm{p}<0.001\end{array}$ & $63.6( \pm 17.0)$ & $50.8( \pm 22.5)$ \\
\hline Depth perception & $91.1( \pm 18.2)$ & $84.4( \pm 24.0)$ & $\begin{aligned} & 82.3( \pm 25.6) \\
& \mathrm{F}=27.51 ; \mathrm{p}<0.001\end{aligned}$ & $84.1( \pm 22.6)$ & $70.7( \pm 28.2)$ \\
\hline Total VF score & $79.5( \pm 14.7)$ & $71.1( \pm 19.1)$ & $\begin{array}{c}68.7( \pm 18.8) \\
\mathrm{F}=52.53 ; \mathrm{p}<0.001\end{array}$ & $69.7( \pm 17.5)$ & $55.8( \pm 22.5)$ \\
\hline \multicolumn{6}{|c|}{ Quality of Life scores (based on those responding) } \\
\hline Self-care & $96.9( \pm 9.9)$ & $92.0( \pm 17.2)$ & $\begin{array}{c}89.1( \pm 21.3) \\
\mathrm{F}= \\
47.45 ; \mathrm{p}<0.001\end{array}$ & $94.9( \pm 13.7)$ & $70.6( \pm 34.8)$ \\
\hline Mobility & $92.5( \pm 17.5)$ & $85.1( \pm 24.3)$ & $\begin{array}{c}74.2( \pm 30.3) \\
\mathrm{F}=61.26 ; \mathrm{p}<0.001\end{array}$ & $85.8( \pm 24.3)$ & $52.3( \pm 38.4)$ \\
\hline Social & $87.4( \pm 21.4)$ & $77.4( \pm 27.6)$ & $\begin{array}{c}62.9( \pm 32.9) \\
\mathrm{F}=64.87 ; \mathrm{p}<0.001\end{array}$ & $74.8( \pm 29.0)$ & $43.6( \pm 36.8)$ \\
\hline Mental & $91.6( \pm 16.5)$ & $86.6( \pm 23.2)$ & $\begin{array}{c}80.6( \pm 31.5) \\
\mathrm{F}=22.84 ; \mathrm{p}<0.001\end{array}$ & $86.5( \pm 27.1)$ & $67.9( \pm 37.5)$ \\
\hline Total QOL score & $92.1( \pm 14.1)$ & $85.3( \pm 20.2)$ & $\begin{array}{c}76.9( \pm 24.8) \\
\mathrm{F}=64.02 ; \mathrm{p}<0.001\end{array}$ & $85.5( \pm 20.5)$ & $58.7(32.3)$ \\
\hline
\end{tabular}

$\mathrm{VI}$ = visual impairment; URE = uncorrected refractive error; SVI = severe visual impairment; VF = visual function; QOL = quality of life 
Table 4. Association of VF/QOL scores with socio-demographic characteristics

\begin{tabular}{|c|c|c|c|c|c|c|c|c|}
\hline \multirow[t]{3}{*}{ Variables } & \multicolumn{4}{|c|}{ Total VF } & \multicolumn{4}{|c|}{ Total $Q O L$} \\
\hline & \multicolumn{2}{|c|}{ Unadjusted OR } & \multicolumn{2}{|c|}{$\begin{array}{c}\text { Adjusted } O R \\
\text { (adjusted for PVA) }\end{array}$} & \multicolumn{2}{|c|}{ Unadjusted $O R$} & \multicolumn{2}{|c|}{$\begin{array}{c}\text { Adjusted } O R \\
\text { (adjusted for PVA) }\end{array}$} \\
\hline & $\begin{array}{c}\text { Mean } \\
{[95 \% \text { CI] }}\end{array}$ & $\begin{array}{c}\text { OR } \\
(P \text { value })\end{array}$ & $\begin{array}{c}\text { Mean } \\
{[95 \% \text { CI }]}\end{array}$ & $\begin{array}{c}\text { OR } \\
\text { (P value })\end{array}$ & $\begin{array}{c}\text { Mean } \\
{[95 \% \text { CI] }}\end{array}$ & $\begin{array}{c}\text { OR } \\
(P \text { value })\end{array}$ & $\begin{array}{c}\text { Mean } \\
{[95 \% \text { CI] }}\end{array}$ & $\begin{array}{c}\text { OR } \\
(P \text { value })\end{array}$ \\
\hline \multicolumn{9}{|l|}{ Age } \\
\hline$<50$ years & 79.6 [77.8-81.4] & $5.2(<0.001)$ & $75.4[73.3-77.5]$ & $1.3(0.2)$ & 93.9 [92.6-95.3] & $20.6(<0.001)$ & $89.7[87.5-92.0]$ & $4.9(<0.001)$ \\
\hline$\geq 50$ years & 72.1 [71.3-72.9] & Ref & $72.8[72.0-73.6]$ & Ref & $85.3[84.3-86.2]$ & Ref & $85.9[85.1-86.8]$ & Ref \\
\hline \multicolumn{9}{|l|}{ Sex } \\
\hline Male & 74.4 [73.2-75.7] & $1.5(0.001)$ & $74.1[72.9-75.3]$ & $1.3(0.04)$ & 88.2 [86.9-89.4] & $1.6(0.002)$ & $87.8[86.5-89.1]$ & $1.4(0.04)$ \\
\hline Female & 72.4 [71.4-73.3] & Ref & 72.6 [71.7-73.5] & Ref & $85.4[84.3-86.5]$ & Ref & $85.7[84.7-86.7]$ & Ref \\
\hline \multicolumn{9}{|l|}{ Residence } \\
\hline Urban & $76.2[74.1-78.4]$ & $1.0(0.7)$ & $75.8[73.8-77.8]$ & $1.1(0.74)$ & 91.6 [89.8-93.5] & $1.7(0.04)$ & $91.2[89.0-93.4]$ & $2.0(0.02)$ \\
\hline Rural & 72.7 [71.8-73.5] & Ref & 72.7 [71.9-73.5] & & $85.6[84.7-86.6]$ & Ref & 85.73 [84.9-86.6] & Ref \\
\hline \multicolumn{9}{|l|}{ Literacy } \\
\hline$\leq$ Secondary & $68.6[67.3-70.0]$ & $0.7(<0.001)$ & $70.0[68.8-71.2]$ & $0.7(0.01)$ & 81.0 [79.4-82.7] & $0.23(<0.001)$ & 82.4 [81.1- 83.7] & $0.5<0.001)$ \\
\hline$>$ Secondary & 75.7 [74.8-76.6] & Ref & 74.9 [74.0-75.9] & Ref & 89.6 [88.7-90.5] & Ref & 88.8 [87.8-89.8] & Ref \\
\hline \multicolumn{9}{|c|}{ Social Status } \\
\hline Upper SES & 74.1 [72.9-75.3] & Ref & 73.5 [72.3-74.6] & Ref & $86.8[85.5-88.0]$ & Ref & 86.1 [84.8-87.8] & Ref \\
\hline Lower SES & $72.5[71.5-73.5]$ & $0.8(0.04)$ & 72.9 [72.0-73.9] & $1.0(0.7)$ & $86.3[85.2-87.4]$ & $0.7(0.02)$ & 86.7 [85.7-87.8] & $0.9(0.7)$ \\
\hline
\end{tabular}

\section{Discussion}

Individuals with the same distance VA may have varying degrees of difficulty in undertaking visual tasks, and the loss of vision may have a different impact on their quality of life. Measuring these parameters, is therefore of value for complementing traditional clinical tests [7].

Many studies have documented that VF and QOL scores parallel VA measures $[10,14-16,18,19]$. For example, in China, best-corrected VA in the better eye was the most important determinant of vision-related QOL [18].

We observed a linear relationship between level of visual impairment and VF and QOL scores. This means that the worse the vision, the lower the VF and QOL score. Our study corroborates the findings of other studies in many countries such as Malawi [10], China [18,19], Hong Kong [20], Singapore [21,22], Nigeria [16], Pakistan [14] and India [23]. These studies highlight that the functional and psychological impacts of visual impairment are similar across populations [9] despite differences in culture, roles, levels of social support and access to services. In our study, the impact on VF and QOL was greater for individuals with lower levels of education, which was independent of SES. This finding is difficult to interpret but may reflect poorer coping skills or poorer access to health education or relevant services.
In the present study, the lowest VF and QOL scores were amongst those who were severely visually impaired or blind from cataract. Similar findings have been reported from Bangladesh [17], China [18], Singapore [21] and India [23,25].

Our results show that the cataract-operated group (even though they had vision $>6 / 60$ ) had significantly lower scores than the normal vision group and also marginally lower than those with refractive error related visual impairment, which probably reflects suboptimal outcomes after cataract surgery [15] also for the one eye operated participants it could be some of them have cataract or other eye problem in the second eye. Only a sub analysis of this group could explain this. In this national survey 345 participants had undergone cataract surgery in one or both eyes (486 eyes) and almost $40 \%$ of operated eyes had a PVA of $<6 / 18$. Similar findings were also highlighted from a study from Pakistan [14]. These findings show that attention needs to be paid to the quality of cataract surgery to enable patients to lead full and independent lives after surgery.

Even moderately visually impaired persons (PVA $<6 /$ 18-6/60 in the better eye) had poorer VF and QOL scores for almost all the domains than the normal vision group. This shows that any drop in VA has a profound impact on 
the day-to-day lives of those affected. In the Singapore Malay Eye Study participants with severe unilateral and bilateral vision impairment had significantly worse visionspecific functioning than those with no impairment, regardless of literacy [21].

There has only been one earlier study in Sri Lanka, which focussed on VF among an elderly population with and without cataract. A limitation of this study is that it did not relate the findings to VA [24].

Most studies report the use of VF and QOL questionnaires as a means of monitoring the outcome of cataract surgery $[4,6,7,12,15,17-20]$ but these instruments also have the potential to enrich patient-management and follow-up for other eye conditions. For example, in studies from Pakistan [14], Nigeria [16] and Singapore [22] VF/QOL scores were lower for those who were visually impaired from glaucoma than from cataract. A study in India assessed VF and QOL scores in individuals with a range of eye conditions, showing that VA was an important predictor of low scores in individuals with cataract or retinal pathology but not in those with glaucoma and corneal disease [25]. In our study, the number of individuals with vision loss from glaucoma, diabetic retinopathy or corneal conditions was too low for separate analysis.

Our results show that the VF/QOL questionnaires provide valuable information not only in visual impairment but also for the specific causes leading to visual impairment. The wide variation in scores both within and across the vision categories points to the complementary role of other factors which was highlighted in the present analysis and was alluded to in the results from Nigeria where after controlling for VA, VF and QOL scores were significantly lower among specific groups [16]. Our results show that socio-demographic factors also directly impact VF and QOL scores as adjusting for PVA still showed strong associations.

There are some limitations to our study. As in the study in Nigeria, we did not collect data on co-morbidities (e.g. osteoarthritis, hearing or intellectual impairment etc.), personal and environmental factors (individual's coping ability, social support mechanisms, familial support etc.). Another limitation is that contrast sensitivity, which is recognized to strongly influence visual functioning, was not measured. Since VF/QOL questionnaires depend on participants' self-reported responses, we do not know whether reporting bias played a role.

This is the first large population-based study to highlight the importance of VF and QOL among the visually impaired adult population in Sri Lanka. These data can help to prioritize people's need for vision to enable them to undertake regular socially productive and life-enhancing activities in their day-to-day lives. Ensuring that individuals can regain independence and live fulfilled lives after cataract surgery will become even more important given the increase in the ageing population and worsening dependency ratios.

\section{Acknowledgements}

We acknowledge the support from the members of the Steering Committee, the Sri Lanka College of Ophthalmologists, the Vision2020 Secretariat, Ministry of Health \& Family Welfare, Sri Lanka, Sightsavers Country Office, Sri Lanka and all the supervisors and field investigators (Madhuni Wijepala, Subhashini Deshappriya, Rasika Damayanthi, Dinusha Sandamali, Ashanti de Silva, Chaturika Madushani, Menaka Rathnayake, Madusha Priyadarshini, Nadeesha Dilhani, Gaya Shanthi) and data entry operators (Sunethra Thennakoon, Kumuduni Sriyalatha) who worked with great diligence in collecting the data from the survey participants. We thank all the survey participants for giving us the time and opportunity to interact with them to collect critical data.

We would like to thank Sightsavers for financial support of the overall study and CBM for financial contributions to the disability component of the survey.

\section{Conflicts of interest}

All authors declare that they do not have any conflicts of interest.

\section{References}

1. Ellwein LB, Fletcher A, Negrel AD, Thulasiraj RD. Quality of life assessment in blindness prevention interventions. Inter Ophthalmol 1995; 18: 263-8.

2. Gardiner AM, Armstrong RA, Dunne MCM, Murray PI. Correlation between visual function and visual ability in patients with uveitis. Br J Ophthalmol 2002; 86: 993-6.

3. Seddon J, Fong D. Visual Function Assessment Questionnaires. Surv Ophthalmol 2001; 45: 531-48.

4. Elliot DB, Hurst MA, Weatherill J. Comparing clinical tests of visual function in cataract with the patients perceived visual disability. Eye 1990; 4: 712-7.

5. Frost NA, Sparrow JM, Durrant JS, Donovan JL, Peters TJ, Brookes ST. Development of a questionnaire for measurement of vision-related quality of life. Ophthalmic Epidemiol 1998; 5: 185-210.

6. Steinberg EP, Tielsch JM, Schein OD, et al. The VF-14- An index of functional impairment in patients with cataract. Arch Ophthalmol 1994; 12: 630-8.

7. Fletcher AE, Ellwein LB, Selvaraj S, Vijaykumar V, Rahmatullah R, Thulasiraj RD. Measurements of Vision function and quality of life in patients with cataracts in South India: Report of instrument development. Arch Ophthalmol 1997; 115: 767-74.

8. Mangione CM, Lee PP, Gutierrez PR, Spritzer K, Berry S, Hays RD. Development of the 25-item National Eye 
Institute Visual Function Questionnaire. Arch Ophthalmol 2001; 119: 1050-8.

9. Murthy GV, Gupta SK, Thulasiraj RD, Vishwanath K, Donoghue EM, Fletcher AE. The development of the Indian Visual Functioning Questionnaire: questionnaire content. Br J Ophthalmol 2005; 89: 498-503.

10. Dijk KV, Lewallen S, Chirambo M et al. Creation and testing of a practical visual function assessment for use in Africa: correlation with visual acuity, contrast sensitivity, and near vision in Malawian adults. Br J Ophthalmol 1999; 83: 792-5.

11. World Health Organization. Coding Instructions for the WHO/PBL Eye Examination Record (Version III). Geneva, Switzerland: WHO, 1988:PBL/88.1.

12. Polack S, Kuper H, Mathenge W, Fletcher A, Foster A. Cataract visual impairment and quality of life in a Kenyan population. Br J Ophthalmol 2007; 91: 927-32.

13. Schemann JF, Leplege A, Keita T, Resnikoff S. From visual function deficiency to handicap: measuring visual handicap in Mali. Ophthalmic Epidemiol 2002; 9: 133-48.

14. Taylor AE, Shah SP, Gilbert CE, et al. Visual function and quality of life among visually impaired and cataract operated adults. The Pakistan National Blindness and Visual Impairment Survey. Ophthalmic Epidemiol 2008; 15: 242-9.

15. Pokharel GP, Selvaraj S, Ellwein LB. Visual functioning and quality of life outcomes among cataract operated and unoperated blind populations in Nepal. Br J Ophthalmol 1998; 82: 606-10.

16. Tran HM, Mahdi AM, Sivasubramaniam S, et al. Quality of life and visual function in Nigeria: findings from the national survey of blindness and visual impairment. $\mathrm{Br} J$ Ophthalmol 2011; 95: 1646-51.
17. Polack S, Kuper H, Wadud Z, Fletcher A, Foster A. Quality of life and visual impairment from cataract in Satkhira district, Bangladesh. Br J Ophthalmol 2008; 92: 1026-30.

18. Zhu M, Yu J, Zhang J, Yan Q, Liu Y. Evaluating visionrelated quality of life in preoperative age-related cataract patients and analysing its influencing factors in China: a cross-sectional study. BMC Ophthalmology 2015; 15: 160.

19. He M, Xu J, Li S, Wu K, Munoz SR, Ellwein LB. Visual acuity and quality of life in patients with cataract in Doumen county, China. Ophthalmology 1999; 106: 1609-15.

20. Lau J, Michon JJ, Chan WS, Ellwein LB. Visual acuity and quality of life outcomes in cataract surgery patients in Hong Kong. Br J Ophthalmol 2002; 86: 12-17.

21. Chiang PPC, Zheng Y, Wong TY, Lamoureux EL. Vision impairment and major causes of vision loss impacts on vision-specific functioning independent of socio-economic factors. Ophthalmology 2013; 120: 415-22.

22. Lamoureux EL, Chong EW, Thumboo J, et al. Vision Impairment, ocular conditions and vision-specific function: The Singapore Malay Eye Study. Ophthalmology 2008; 115: 1973-1981.

23. Nirmalan PK, Tielsch JM, Katz J, et al. Relationship between vision impairment and eye disease to visionspecific quality of life and function in rural India: the Aravind Comprehensive Eye Survey. Invest Ophthalmol Vis Sci. 2005; 46: 2308-12.

24. Nanayakkara S. Vision-related quality of life among elders with cataract in Sri Lanka: Findings from a study in Gampaha district. Asia Pac J Public Health 2009; 21: 303-11.

25. Nutheti R, Shamanna BR, Nirmalan PK, et al. Impact of impaired vision and eye disease on quality of life in Andhra Pradesh. Invest Ophthalmol Vis Sci. 2006; 47: 4742-8. 